\title{
INVESTIGATION OF HYDRAULIC, GEOTECHNICAL, AND PLANNING ASPECTS FOR THE ENVIRONMENTAL SAFETY OF THE NEW SPORT FACILITIES IN L'AQUILA
}

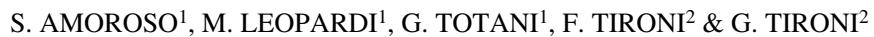 \\ ${ }^{1}$ Department of Structural, Water, and Geotechnical Engineering, University of L'Aquila, Italy. \\ ${ }^{2}$ Department of Architecture and Urban Planning, University of L'Aquila, Italy.
}

\begin{abstract}
The earthquake of L'Aquila (on 6 April 2009) has resulted in a pressing need to provide the city with hospitality areas and new structures for the population. In the territory of L'Aquila, the lack of space and the inhabitability of sport facilities make the case study below compelling. In rivers, hydraulic hazards are the result of either natural or human factors. The first step in addressing the problem is to establish hydraulic safety measures: this work must include the improvement of the hydraulic characteristics of rivers in order to create a section compatible with the maximum predictable height and flow. The logic of mitigation works for hydraulic hazards usually does not coincide with river redevelopment measures because some actions are obviously conflicting. The issues dealing with mitigation works are related to geotechnical and hydraulic research, and the use of natural materials. This paper aims to illustrate a diagnostic functionality of the embankments of the Aterno River (L'Aquila, Italy) and its surrounding areas. The definition of hydraulic and geotechnical properties allows the integration of hydraulic safety measures with extra-agricultural use of the territory. In fact, in this area, mitigation works are combined with the plan of the city and of sports and leisure time, applying measures that have a different environmental impact. The river embankments, for example, are embedded in the spatial and functional organization of the planned sport facilities.
\end{abstract}

Keywords: City of sports and leisure time, environmental impact, hydraulic hazard, mitigation works, multifunctional sport facilities, soil properties.

\section{INTRODUCTION}

All along the river course, embankments are subject to instability phenomena. In particular, floods may cause the breaking of the banks due to flow, filtration, and rainfall. From an assessment of these problems, it is possible to identify geotechnical aspects in order to restore the river embankments. Therefore, in situ tests, laboratory tests, and water pressure measures along the Aterno River are important as they indicate better design solutions for establishing hydraulic safety works with low environmental impact.

\section{THE ATERNO RIVER}

During recent years, in the suburbs of L'Aquila, the agricultural lands have been replaced by civil and industrial structures and facilities; and the buildings have extended into the valley depression, so affecting the fluvial processes within the Aterno River (Fig. 1). Today, it is necessary to check the appropriateness of the existing defense works, and to hold to account the above mentioned modification of the use of the territory, particularly where the river is embanked.

In this article, we describe the conservative-functional solutions to keep the morphologic and structural layout of the fluvial section unchanged, by using adjustment measures of the transversal sections, reinforcing longitudinal defense works, and recovering natural characteristics of the river bed and its closed areas. 


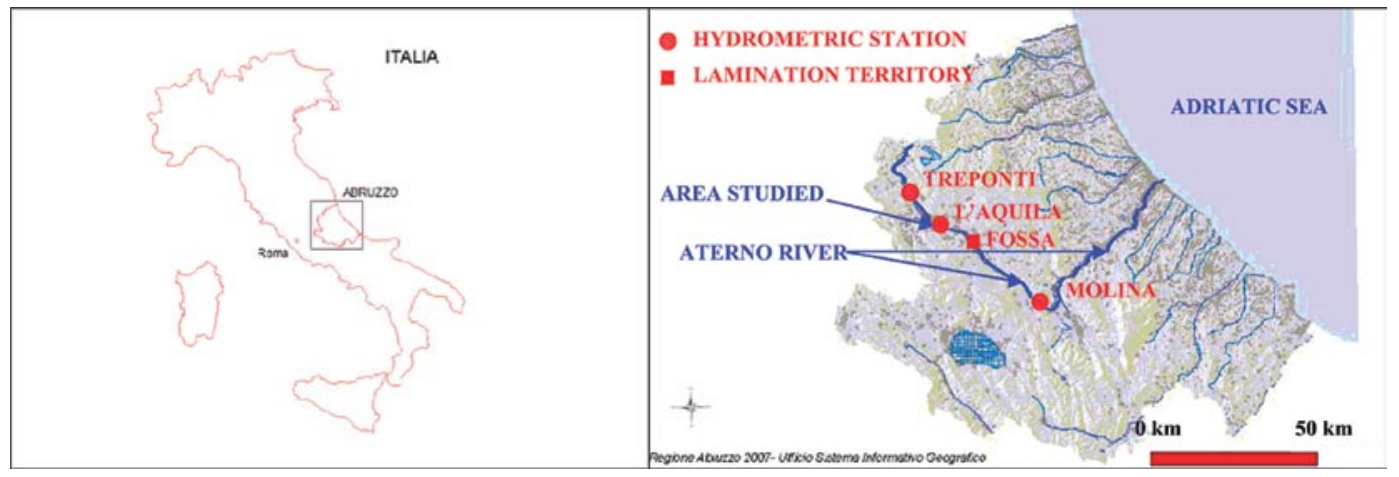

Figure 1: Aterno River and L'Aquila in Abruzzo's regional map.

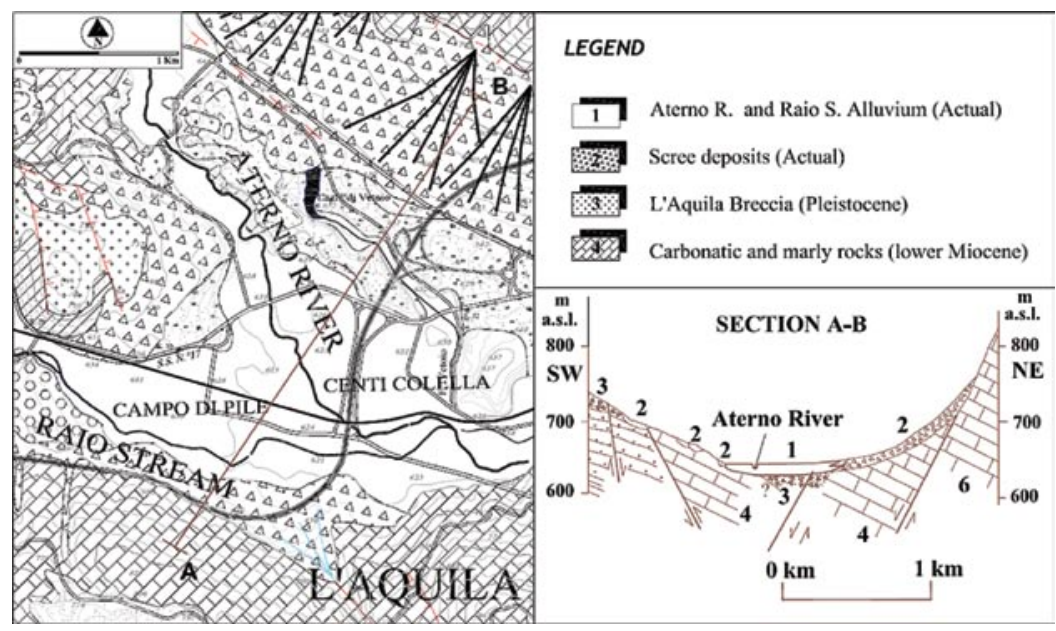

Figure 2: Geologic aspect of L'Aquila basin.

\subsection{Geological setting}

The L'Aquila basin (Fig. 2), extending in the northwest-southeast direction, is a wide depression of tectonic origin enclosed between high mountains, and formed mostly by carbonate rocks, and subordinately, sandstones of the Meso-Cenozoic period, Tallini et al. [2], Bertini et al. [3].

The bottom of the depression was filled in the Pleistocene period with continental environment deposits. Currently, it holds immense plains of recent (Holocene) alluvial filling from the Aterno River and Raio Stream, the main affluent on the right-hand side.

The most ancient continental deposits form wide level areas, which are placed at several heights on the valley plains of the two watercourses. Finally, inside the basin, mountains of modest height emerge that are constituted of rocky outcrops of the Meso-Cenozoic basement.

The alluvial sediments, emerging in the lower-valley plains of the Aterno River and the Raio Stream, are constituted by gravel that variously alternates to lens and levels of sand, sandy, and/or clay silt, silty clay of dark color; the thickness reaches $10-12 \mathrm{~m}$ in the Aterno and Raio plains. 
The deposits are supported by surfaces of variously modeled erosion on several continental sediments or bedrock. The basic geology of L'Aquila basin is illustrated in Fig. 2.

\subsection{Hydrologic and hydraulic studies}

The Aterno River originates in the Gran Sasso-Monti Laga National Park and flows from its source in the Capo Cancelli Mountain in the Velino-Sirente Regional Park. Along its course, it receives contributions from tributaries that come from sources in carbonate rocks. From the initial medium flow (i.e. about 24 1/s, estimated value in some decades of observation), the flow increases mostly in the L'Aquila basin, due to the Vetoio, Raio, and Vera Rivers. The global flow is characterized by a normal regime of variability during all the hydrologic years. However, in the past (the last event happened in December 1999) some floods have caused considerable damage and safety risks.

In the basin of L'Aquila, the Aterno River is completely channeled and it is embanked along the extended stretches of the river due to previous hydraulic works (1880-1950). During this period, some mills with intake constructions were built for productive activities.

From 1952, the urbanization process marks the decrease of traditional activities, such as fragmented and widespread farming. It burdens the territory with infrastructures, preventing the access and use of the river belt and determining the social-cultural detachment from the city, with consequent degradation and abandonment.

Today, geotechnical and hydraulic research are necessary to design and build protection works with an eco-friendly engineering approach. It is possible, if one assumes that the river belt (Fig. 3a) can have an important role in an ecologic valorization. The river belt could become a River Park where people can spend leisure time and, thus, reduce the environmental impact.

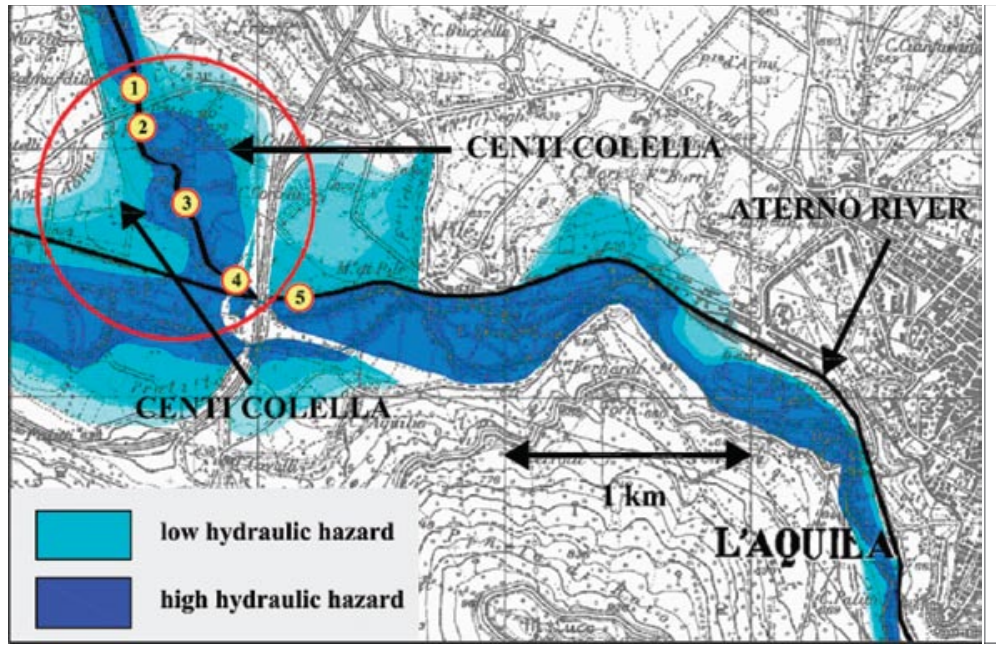

(a)

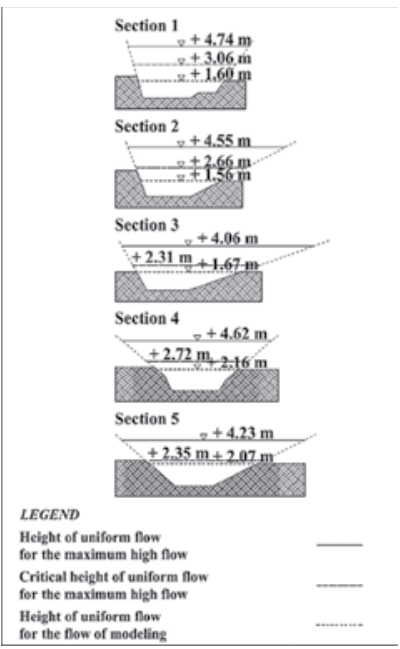

(b)

Figure 3: (a) Map of hydraulic hazard of the Aterno River and section of study and (b) river sections with the ordinary high flow. 


\subsection{Hydrological characteristics of the Aterno River}

The data of the hydrographic service describe the hydrologic characteristics of the Aterno River that underline a paucity of superficial flow, with an annual medium rainfall of $900 \mathrm{~mm}$, and with an extension of the basin of about $1342 \mathrm{~km}^{2}$. This aspect is related to the high permeability of the basin.

The goal is to determine the maximum high flow and the direct measures of flow that have been used in three stations distributed along the Aterno River: Treponti, L'Aquila, and Molina (Table 1).

According to the statistics of the maximum value observed, one procedure is the elaboration of the probability distribution of maximum flow values, for a fixed recurrence time ( $T=200$ years), $Q(T)$, with reference to the function of Gumbel's distribution EV1. In addition to this procedure, the function $Q(T)$ is acquired either with the statistical method of the moments or with the statistical method of the maximum verisimilitude Alessandroni et al. [7], Leopardi et al. [8]. In Table 2, the results obtained in the stations using the various methodologies are summarized.

Probability distribution cannot always be identified through the analysis of frequency distribution. Therefore, objective procedures are required in order to establish whether Gumbel's law is applicable or not. This involves the choice of both the distribution function and all the values related to the parameters that determine the form of the function mentioned above. In this case, the Pizzetti-Pearson method cannot be applied because it requires a greater amount of data. As a result, the Kolmogorov-Smirnov method, known as method of the Fiduciary Bands, has been used. In fact, the latter can be employed independently from the dimension of the data sample and does not require any classification. This method allows the choice of retaining the hypothesis of the function of Gumbel's distribution in order to interpret the three statistical series (Fig. 4).

Table 1: Characteristics of the hydrometric stations.

\begin{tabular}{|c|c|c|c|c|}
\hline $\begin{array}{l}\text { Hydrometric } \\
\text { stations }\end{array}$ & $\begin{array}{l}\text { Area of the basin } \\
\qquad\left(\mathrm{km}^{2}\right)\end{array}$ & $\begin{array}{c}\text { Basin permeability } \\
(\%)\end{array}$ & $\begin{array}{l}\text { Medium altitude of } \\
\text { all the basin until the } \\
\text { station (m a.s.l.) }\end{array}$ & $\begin{array}{l}\text { Hydrometric zero } \\
\text { (m) }\end{array}$ \\
\hline Treponti & 114 & 34 & 1026 & 760.00 \\
\hline L'Aquila & 531 & 46 & 1105 & 640.00 \\
\hline Molina & 1303 & 60 & 1120 & 435.00 \\
\hline
\end{tabular}

Table 2: Values of the maximum flow and the specific flow with $T_{\mathrm{r}}=200$ years.

\begin{tabular}{|c|c|c|c|c|c|c|}
\hline \multirow[b]{2}{*}{$\begin{array}{l}\text { Measure } \\
\text { stations }\end{array}$} & \multicolumn{2}{|c|}{$\begin{array}{l}\text { Method of the maximum } \\
\text { observed value }\end{array}$} & \multicolumn{2}{|c|}{ Method of the moments } & \multicolumn{2}{|c|}{$\begin{array}{l}\text { Method of maximum } \\
\text { verisimilitude }\end{array}$} \\
\hline & $\begin{array}{c}Q_{200} \\
\left(\mathrm{~m}^{3} / \mathrm{s}\right)\end{array}$ & $\begin{array}{c}q_{200} \\
\left(\mathrm{~m}^{3} / \mathrm{s} / \mathrm{km}^{2}\right)\end{array}$ & $\begin{array}{c}Q_{200} \\
\left(\mathrm{~m}^{3} / \mathrm{s}\right)\end{array}$ & $\begin{array}{c}q_{200} \\
\left(\mathrm{~m}^{3} / \mathrm{s} / \mathrm{km}^{2}\right)\end{array}$ & $\begin{array}{c}Q_{200} \\
\left(\mathrm{~m}^{3} / \mathrm{s}\right)\end{array}$ & $\begin{array}{c}q_{200} \\
\left(\mathrm{~m}^{3} / \mathrm{s} / \mathrm{km}^{2}\right)\end{array}$ \\
\hline Treponti & 73 & 0.64 & 71 & 0.62 & 60 & 0.52 \\
\hline L'Aquila & 329 & 0.62 & 319 & 0.60 & 354 & 0.66 \\
\hline Molina & 124 & 0.09 & 121 & 0.09 & 109 & 0.08 \\
\hline
\end{tabular}


From the analysis of the stations' values of flow at their fullest, it is pointed out that for the Molina station, which is contrary to what is expected, the flows are clearly inferior compared to that of the L'Aquila's station, although the subtended basin is more than double. The cause is to be sought out in the lamination effect produced by the overflow of the Aterno River in the Territory of Fossa (Fig. 5).
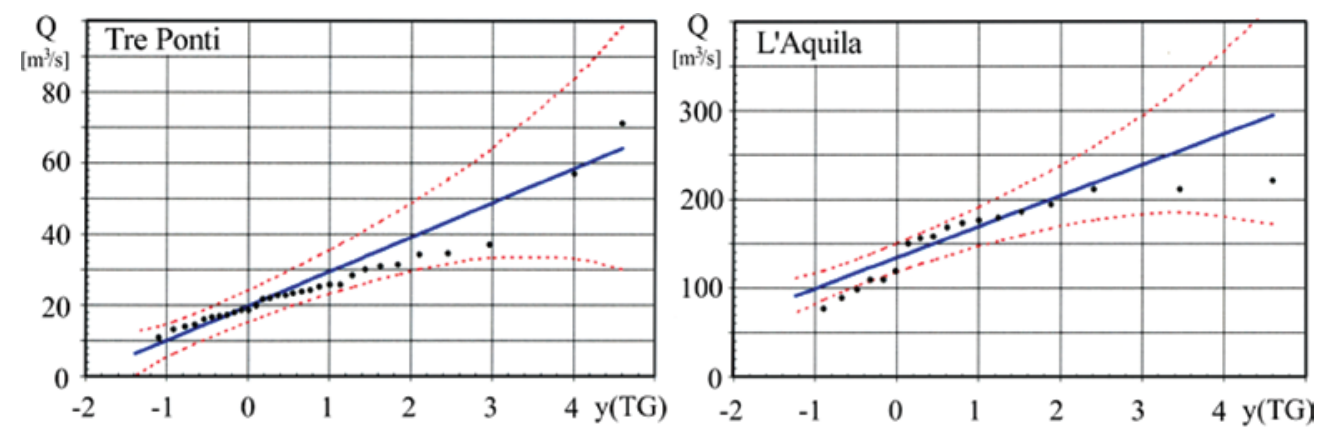

- Gumbel law • data

Fiduciary Bands $\cdots \cdot \mathrm{FF}+$

$\mathrm{y}(\mathrm{TG})$ plotting position

$$
\begin{aligned}
& \mathrm{y}(T \mathrm{G})=-\ln \cdot\left[-\ln \left(1-T_{\mathrm{G}}{ }^{-1}\right)\right] \\
& T_{\mathrm{G}}=\frac{\mathrm{N}+0,12}{\mathrm{i}-0,44}
\end{aligned}
$$

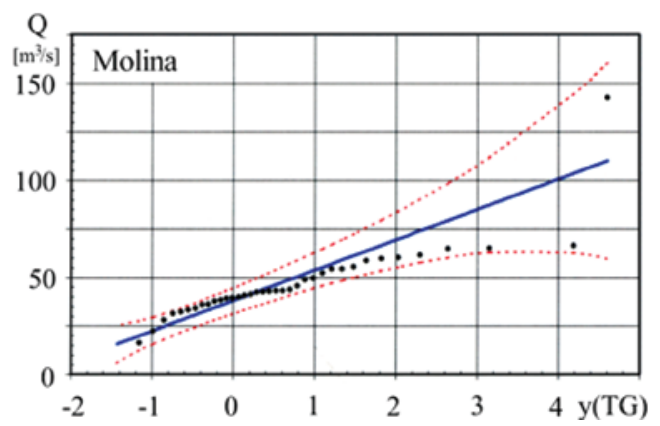

Figure 4: Method of the Fiduciary Bands.

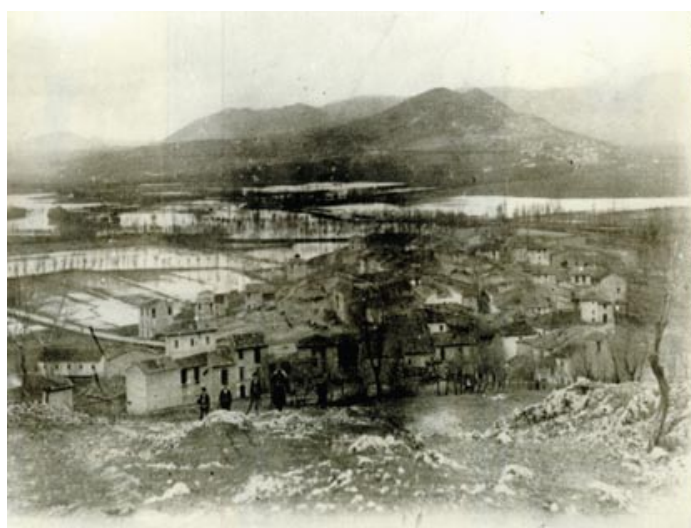

(a)

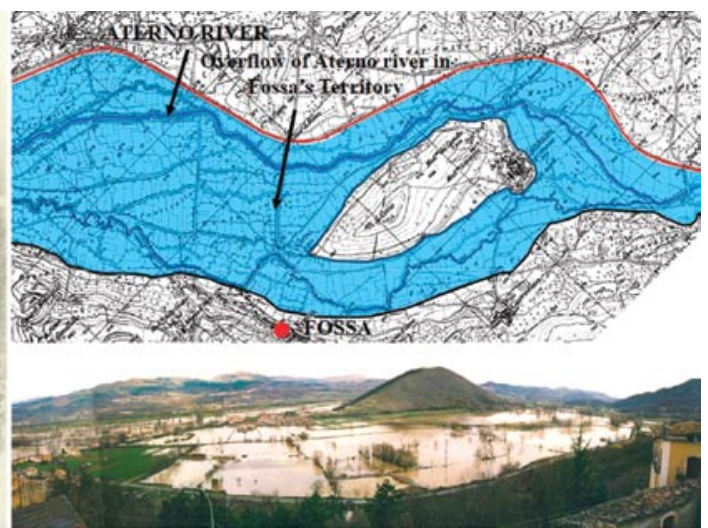

(b)

Figure 5: (a) Overflow of the Aterno River in the Territory of Fossa (1900) and (b) overflow of the Aterno River in the Territory of Fossa (15 December 2003). 
2.4 Analysis of the results and evaluation of design maximum flow

Riverside areas that have moderate flow probability should be defined considering a flow for a fixed recurrence time ( $T_{\mathrm{r}}=200$ years), $Q\left(T_{\mathrm{r}}\right)$ in the approximately $276 \mathrm{~km}^{2}$ region of the Aterno River basin.

Flow values (Table 2) have a sensitive range of variability coming from the different procedures for the evaluation of design maximum flow. In order to obtain the likeliest value of $Q(T)$, the data sample distribution is considered normal, Leopardi et al. [9]. The flow has an underflow probability of $80 \%$. A normal distribution is fixed by the average, $\propto$, and the standard deviation, $s$. It is possible to transform the normal distribution into a standard one by the variable $z$ :

$$
z=\frac{Q_{\%}-\mu}{\sigma} \text {. }
$$

Moreover, the underflow probability (e.g. 80\%) can be defined according to eqn (2):

$$
P\left(Q \leq Q_{80 \%}\right)=\xi(z)=\xi\left(\frac{Q_{80 \%}-\mu}{\sigma}\right)=80,
$$

where $\xi(z)$ is the normal standard distribution. Through statistics tables, the figure of $80 \%$ refers to the value $z=0.84$. It can be inserted in eqn (1) to estimate the flow values $Q_{80 \%}$ in the sections and in relation to a fixed recurrence time (Table 3 ).

The results are valid and specific for their own data station. In order to evaluate the upstream flow of the station, we suppose that, into a homogeneous hydrological area, the maximum flow values of

\begin{tabular}{|c|c|c|c|c|c|c|}
\hline$T_{\mathrm{r}}$ (years) & $\begin{array}{l}\text { Maximum observed } \\
\text { value }\left(\mathrm{m}^{3} / \mathrm{s}\right)\end{array}$ & $\begin{array}{l}\text { Moments } \\
\left(\mathrm{m}^{3} / \mathrm{s}\right)\end{array}$ & $\begin{array}{l}\text { Maximum verisimilitude } \\
\qquad\left(\mathrm{m}^{3} / \mathrm{s}\right)\end{array}$ & $\propto$ & $\sigma$ & $\begin{array}{r}Q_{80 \%} \\
\left(\mathrm{~m}^{3} / \mathrm{s}\right)\end{array}$ \\
\hline \multicolumn{7}{|l|}{ Tre Ponti } \\
\hline 20 & 50 & 49 & 43 & 47.3 & 3.8 & 50.5 \\
\hline 50 & 59 & 58 & 50 & 55.7 & 4.9 & 59.8 \\
\hline 100 & 66 & 64 & 55 & 61.7 & 5.9 & 66.6 \\
\hline 200 & 73 & 71 & 60 & 68.0 & 7.0 & 73.9 \\
\hline 500 & 82 & 80 & 67 & 76.3 & 8.1 & 83.2 \\
\hline \multicolumn{7}{|l|}{ L'Aquila } \\
\hline 20 & 243 & 238 & 257 & 246.0 & 9.8 & 254.3 \\
\hline 50 & 278 & 270 & 295 & 281.0 & 12.8 & 291.7 \\
\hline 100 & 303 & 295 & 325 & 307.7 & 15.5 & 320.7 \\
\hline 200 & 329 & 319 & 354 & 334.0 & 18.0 & 349.1 \\
\hline 500 & 363 & 351 & 392 & 368.7 & 21.1 & 386.4 \\
\hline
\end{tabular}

Table 3: Flow values $Q_{80 \%}$ in the sections in relation to a fixed recurrence time. 
the two stations could be represented by the scale factor $\propto_{i}$. This is independent from the recurrence time and proper to each river section in the homogeneous area:

$$
Q_{i}(T)=\mu_{i} \cdot Q^{\prime}\left(T_{\mathrm{r}}\right),
$$

where $Q^{\prime}\left(T_{\mathrm{r}}\right)$ is the non-dimensional growth factor, the only one in the considered homogeneous hydrological area.

From the analysis of the maximum flow sample for each of the two stations, growth laws $Q(T)$ have been estimated. Then, they are considered non-dimensional by using flows for a recurrence time of 20, 50,100, 200, and 500 years, which are index flows. Finally, they have been put into the Gumbel's probabilistic diagram (Fig. 6). The closest sheaf is the one related to the index flow for a recurrence time of 200 years. Its growth law is represented by the bisector of the sheaf, whose expression is:

$$
Q^{\prime}\left(T_{\mathrm{r}}\right)=0.1228 \cdot Y\left(T_{\mathrm{r}}\right)+0.3494
$$

The scale factor $\propto_{i}$ has been determined through a statistical analysis of a univaried linear regression. With regard to the index flow $Q^{\prime}(200)$, it is correlated with physics, topographic, morphometric, and pluviometric features of the hydrographic basin. Among all these properties, the independent variable $A_{\mathrm{i}}$, waterproof area, shows the biggest correlation coefficient:

$$
\begin{gathered}
\mu_{\mathrm{i}}=1.3392 \times A_{\mathrm{i}}+21.994 \\
Q_{i}(T)=1.3392 \cdot A_{i}+21.994 \cdot 0.1228 \cdot Y\left(T_{\mathrm{r}}\right)+0.3494 \\
A_{i}=115.6 \mathrm{~km}^{2}, \quad Y\left(T_{\mathrm{r}}\right)=5.29581, \quad Q \cong 177 \mathrm{~m}^{3} / \mathrm{s}
\end{gathered}
$$

\subsection{Hydraulic and geotechnical safety measures}

2.5.1 The plan of hydraulic and environmental compatibility with the municipality projects The design choices come from a comparison between situations and proposals, sometimes in conflict in this urban area.

Presently, there are some sport facilities, but the area was supposed to be reorganized with hydraulic safety measures and space distribution and rationalization of the equipment. Thus, for a correct plan, it would be appropriate to integrate urban aspects with hydraulic and geotechnical problems and with low environmental impact measures.

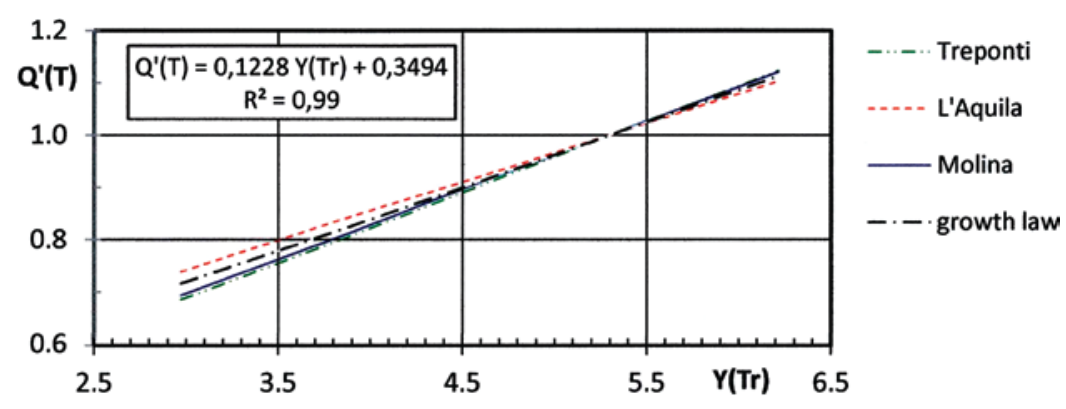

Figure 6: Gumbel's probabilistic diagram. 
It is important to know the geometry of the river sections and the relative heights of gradually varied steady flow for the maximum high flow.

Assuming that the specific flow equals $0.64 \mathrm{~m}^{3} / \mathrm{s} / \mathrm{km}^{2}$ and the area of the basin subtended by the Aterno River in the concerning tract equals $276 \mathrm{~km}^{2}$, the design maximum flow is approximately $177 \mathrm{~m}^{3} / \mathrm{s}$.

From the examination of the planimetric river course (Fig. 3a), and the longitudinal profile of the river bed, there is a rather homogenous course with uniform slopes $(i=0.0046)$. Subdividing the watercourse in homogenous tracts, five meaningful sections have been found. From their examination it can be deduced that the modeling of the river bed, 'bank full,' generally corresponds to the ordinary high flow, with the flow estimated near the mainly embedded part of the transversal sections (Fig. 3b).

Shown in section 5 (Fig. 7a) are the relative heights of flow, calculated (HEC-RAS) for the modeling flow and maximum high flow $\left(177 \mathrm{~m}^{3} / \mathrm{s}\right)$, as well as the calculation for critical height (the same results came out from the other sections).

In order to contain the overflow in the area concerned, a planning solution has been the realization of embankments with the purpose of delimiting and centralizing the river bed of 'bank full' with flood beds, as shown in Figs $7 \mathrm{~b}$ and 8.

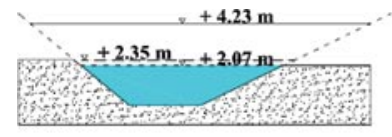

LEGEND

Height of uniform flow for the maximum high flow Critical height of uniform flow for the maximum high flow Height of uniform flow for the flow of modeling

(a)
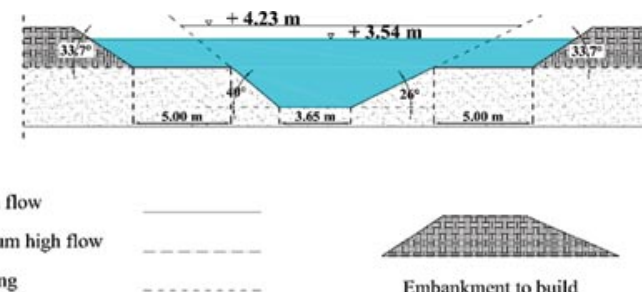

(b)

Figure 7: Section 5. (a) Current section with heights of uniform flow and critical heights for the maximum high flow and (b) design solution.

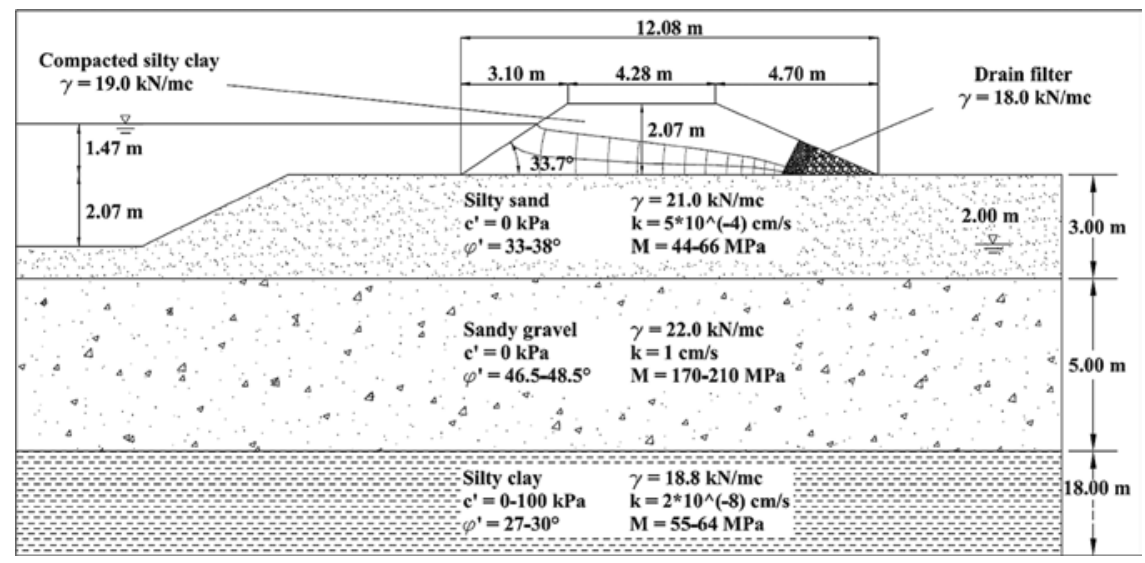

Figure 8: Embankment to realize (section 5), with geotechnical parameters and typical soil layers underlying the embankments in the locality of Campo di Pile. 


\subsubsection{Soil properties}

In the area located before the confluence of the Raio S. in the Aterno R. (zone of Campo di Pile, Centi Colella), an extended geotechnical investigation was carried out by boreholes, Amoroso et al. [1], and in situ and laboratory tests. The flat dilatometer (DMT) test, Marchetti [4], Marchetti et al. [5], has been extensively used with both penetrometer (20 tons) and torpedo-system probe. Numerous standard penetration tests (gravel-sand layers) have been executed and numerous samples (silt-clay layers) have been collected for laboratory tests. The coefficient of permeability of the soil layers has been determined through in situ permeability tests (direct determination) and/or by DMTA dissipation tests (indirect determinations), Marchetti et al. [5], Totani et al. [6]. In Figs 7a, b, and 8, the more meaningful data related to geotechnical parameters, stratigraphy, permeability, and physical-mechanical properties have been presented. The ground water level is located $2 \mathrm{~m}$ below the ground level.

The coefficient of consolidation $c_{\mathrm{v}}$ in the clayey substrate is equal approximately to $2.30 \times 10^{-3}$ $\mathrm{cm}^{2} / \mathrm{s}$. The calculation of settlements shows that the foundation soil is suitable to build an embankment about $2 \mathrm{~m}$ high (Fig. 8). The first bottom, created by the embankment, could be used for maintenance work and for recreational activities.

Numerous particle-size distribution tests have been performed to check if the alluvium soils in the area of study are suitable to be used as fill materials to build the embankments.

\subsubsection{Mitigation works and measures with low environmental impact}

In order to combine the reduction of the hydraulic hazard with low environmental impact measures, innovative solutions could be introduced in the sections of study, using both natural materials as well as new work methods.

Figure 9a shows one of the most appropriate design solutions: Reno mattress. It consists of double twist wire mesh filled with rockfill and top soil. Above this layer, there is the bio-mac to avoid the washout. Thus, it will be realized a mulch hydro-sowing to get a better regeneration of the vegetation.

Another solution is the reinforced soil (Fig. 9b): double twist wire meshes are fitted into the soil layers to increase the tensile strength of the soil. Moreover, it is important to insert willow cuttings and a wire mesh gabion, as foundation, in order to avoid the work scouring.

\section{THE CITY OF SPORT AND LEISURE TIME}

This feasibility study suggests an integration attempt between the hydraulic safety measures and the ways of using the areas hit by the urbanization process in order to shape the City of sport and leisure time in the Centi-Colella area.

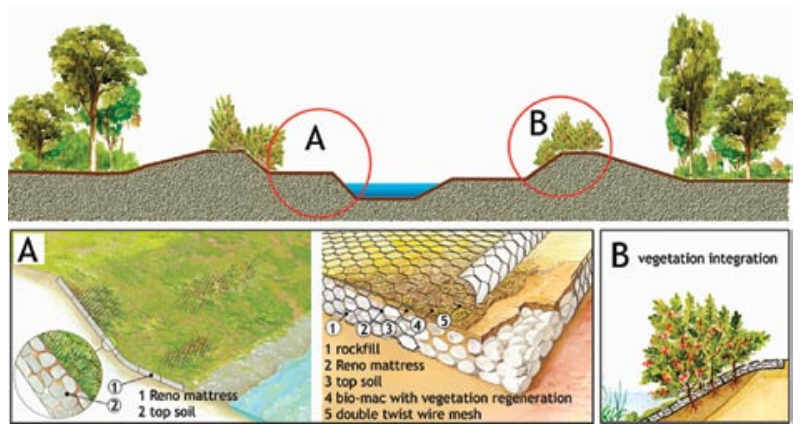

(a)

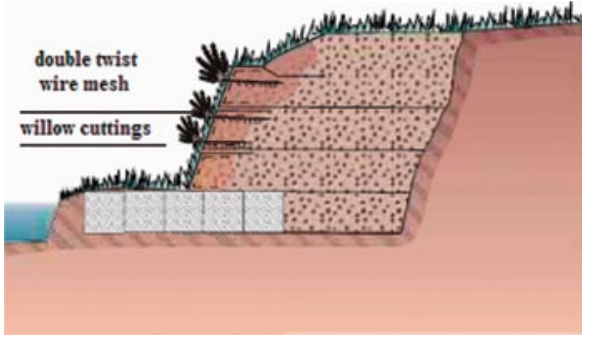

(b)

Figure 9: (a) Reno mattress and (b) reinforced soil. 
This proposal has different aims:

- to introduce the City of sport and leisure time in the L'Aquila environmental system taking into account both 'forecasts' of the planning instruments of different levels (Regional Reference Frame, Regional Landscape Plan, Provincial-Territorial Plan, Urban Development Plan), and, if possible, of the 'state of the art';

- to make the City of sport and leisure time compatible with the guidelines defined by the Flood Defense Plan (Basin Plan of the river Aterno-Pescara);

- to define an integrated complex of sport equipment with type, size, and technologic features which make them multi-functional;

- to define one system as reference to create the various types of equipment following a priority order related to the needs and available economic resources.

At the same time, in an iterative process, to develop the different aspects and to make them coherent to each other, the feasibility study is divided into the following parallel steps:

- the environmental and urban contextualization of the project;

- the definition of the hydraulic safety measures in Centi-Colella;

- the use of the hydraulic defense work in the space and the functional organization of the area;

- the identification of the references used to define the "characteristics of the site', the 'characteristics of the territory', the 'catchment area', the 'characteristics of the sports complex', the 'distribution schemes of the sport complex', and the 'organization schemes of the sport complex';

- the functionality and space organization of the chosen area.

Because of summary needs, only some aspects are listed.

\subsection{Characteristics of the location}

The City of sport and leisure time is to be located in the south west of downtown L'Aquila and its natural base is the river Aterno. This area, which involves the right and left sides of the river's belt, is about $389,000 \mathrm{~m}^{2}$ and it has an altitude between 628.5 and $622.8 \mathrm{~m}$ (a.s.1.), reached, respectively, at the intersections between the river and state route 17, and between the river and highway A 24 .

The area is currently used, in part, by the 'Centi-Colella' sport complex, owned by the city of L'Aquila and its university, in part, by receptive centers and restaurants and, in part, for agricultural activities. It is bordered (Figs 3a and 10a) on the north by the state route (S.S. 17 of the Abruzzo Apennines), on the east by the Highway Roma-L'Aquila-Teramo (A 24), which separates it from an industrial area (Pile), and on the west by a technical equipment zone.

\subsection{The area of study}

The surrounding area of L'Aquila is composed by 43 municipalities and historically it is defined as 'City-Territory.' In this context, the city of L'Aquila is the only inter-municipal center that supplies services. Below an example is described in order to define the strategic role of L'Aquila. It considers the resident population (censuses 1861-2001) as a synthetic indicator of the evolutionary process.

Assuming that:

- the spatial references are Italian territory, Abruzzo region, L'Aquila province, L'Aquila district composed of 43 municipalities, L'Aquila district composed ofy 42 municipalities (L'Aquila municipality is excluded), and L'Aquila municipality; 


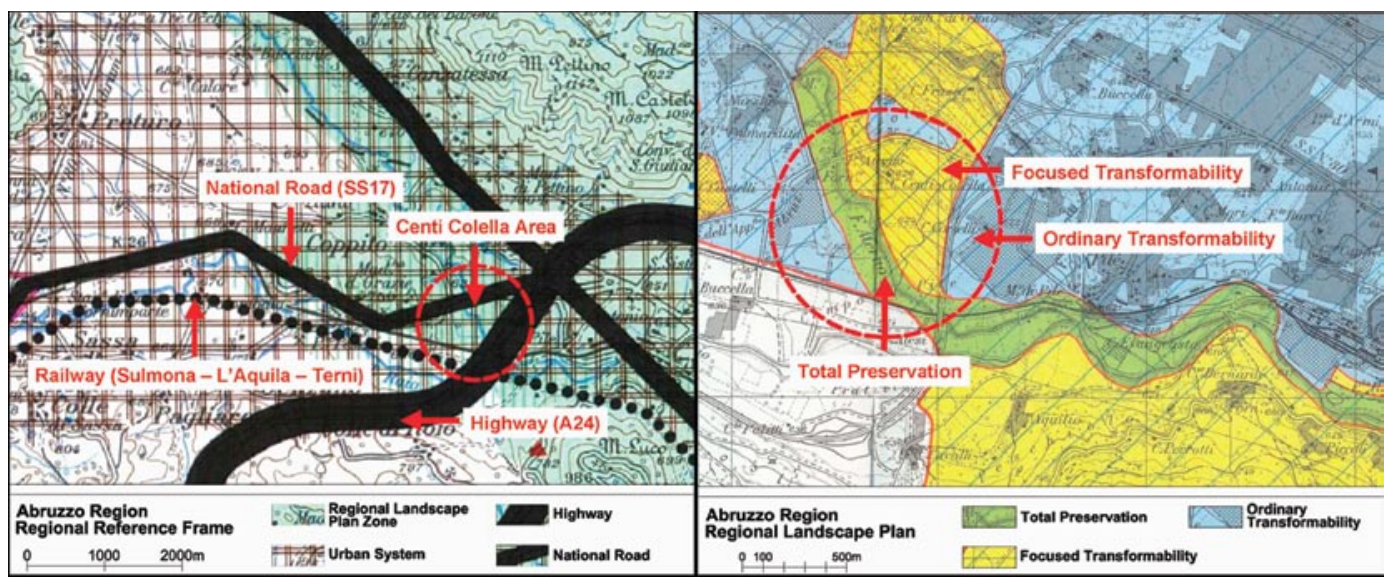

(a)

(b)

Figure 10: (a) Regional reference frame and (b) regional landscape plan.

- the temporal references: the census of 1861 , the census with the higher percentage of resident population in each municipality, the census of 1951 (first census after the second world war and before the Italian economic growth), and the census of 2001 (the latest).

In Italy, the resident population increased:

- $114 \%$ between 1861 and 1951 ;

- 20\% between 1951 and 2001;

- $157 \%$ between 1861 and 2001 .

In Abruzzo, the resident population increased:

- $49 \%$ between 1861 and 1951 ;

- $1 \%$ between 1951 (year in which the population reached the maximum) and 2001;

- 47\% between 1861 and 2001 (the population decreased between 1951 and 1971, while it slowly increased in the latest two censuses of 1991 and 2001).

In the province of L'Aquila, the resident population changed:

- 29\% between 1861 and 1951 (increment);

- 19\% between 1951 and 2001 (decrement);

- $21 \%$ between 1911 (year in which the population reached the maximum) and 2001 (decrement);

- 5\% between 1861 and 2001 (increment).

In the district of L'Aquila (43 municipalities), the resident population changed:

- $17 \%$ between 1861 and 1951 (increment);

- $21 \%$ between 1951 and 2001(decrement);

- 29\% between 1921 (year in which the population reached the maximum) and 2001 (decrement);

- 7\% between 1861 and 2001 (decrement). 
In the district of L'Aquila (42 municipalities, except L'Aquila), the resident population decreased:

- $2 \%$ between 1861 and 1951 ;

- $54 \%$ between 1951 and 2001;

- 64\% between 1921 (year in which the population reached the maximum) and 2001;

- 55\% between 1861 and 2001.

In the municipality of L'Aquila, the resident population increased:

- $63 \%$ between 1861 and 1951;

- $25 \%$ between 1951 and 2001;

- $104 \%$ between 1861 and 2001 (now the population is still increasing).

The data show that the growth of L'Aquila was not enough to balance the decrease of the other 42 municipalities. The consequences are that the district of L'Aquila (43 municipalities) lost its national, regional, and provincial importance, while the city of L'Aquila was going to become the center of a critical area because it lost the rule of 'City-Territory.' These tendencies should be stopped and inverted in order to reach again a territorial equilibrium. It could be possible with different strategic works, for example, through the City of sport and leisure time. This solution assumes importance for the reorganization and development of L'Aquila and its surrounding territory.

The strategic works are indispensable for L'Aquila in order to 'reconquer' and reinforce its provincial and regional role and to project toward national (university campus, capital of mountain peninsular Italy, capital of Abruzzo ski areas) and international competences (research centers).

\subsection{The catchment area}

The potential catchment area consists of 103,951 inhabitants (resident population of the 43 municipalities), where 68,503 people live in L'Aquila $\left(14^{\circ}\right.$ C.G.P.A. I.S.T.A.T., 2001). Moreover, there are 15,000 out-of-town university students (30,000 students attend the University of L'Aquila). Five hundred students attend the Sports Science Department; so they could use the City of sport and leisure time for their activities.

\subsection{Planning references}

In order to define the urban organization of the area and to make this zone become coherent with planning and programmatic documents, these instruments were considered:

- Regional Reference Frame (Fig. 10a): this area belongs to 'Urban System', [13];

- Regional Landscape Plan (Fig. 10b): the zone is classified as 'Integral Preservation' and 'Focused Transformability', [14];

- Provincial Territorial Plan;

- Urban Development Plan (Fig. 11a): the area is finalized to 'Public Green Area' and 'Residential Respect Area', [15];

- Variance of the Urban Development Plan (Fig. 11b): the zone is aimed at 'Recreational and Sport Facilities', [16];

- Basin Plan of the Aterno River (Fig. 3a): the area is related to the hydraulic hazard (very high, high, medium, and moderate), [12];

- Aterno River Park Plan: a bicycle path that runs along the Aterno River crosses the zone. 


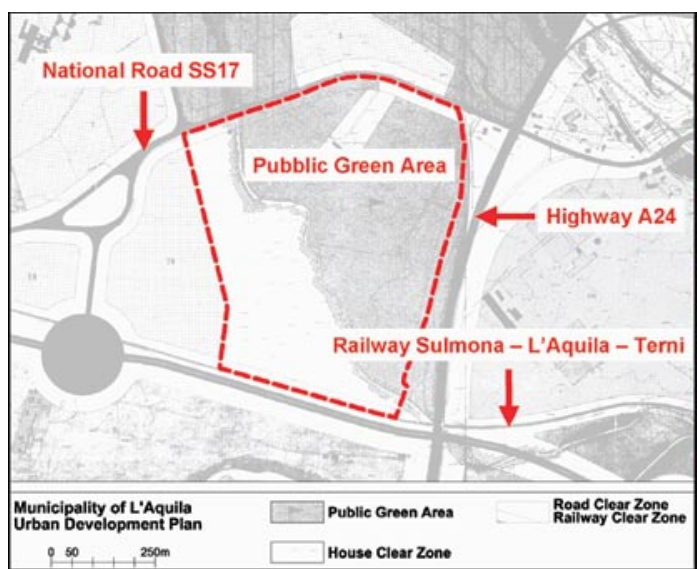

(a)

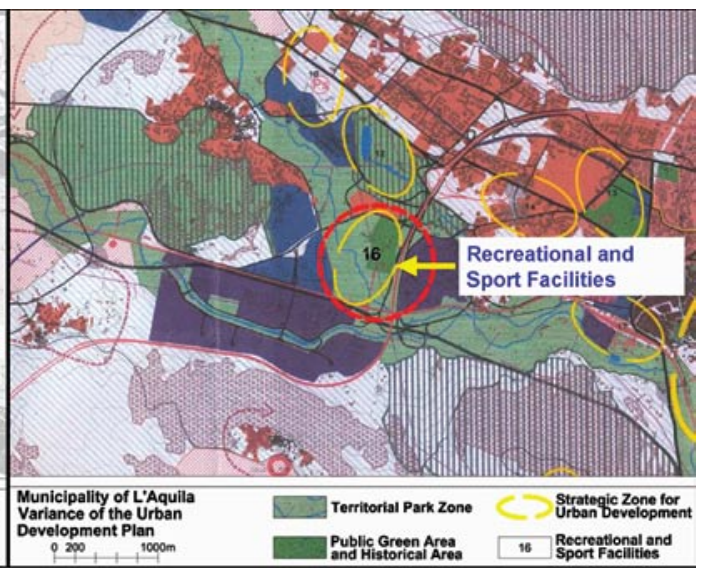

(b)

Figure 11: (a) Urban development plan and (b) variance of the urban development plan.

\subsection{Planning criteria}

The feasibility study of the City of sport and leisure time was proposed in order to plan an urban and territorial center with the following criteria: environmental sustainability, multifunctionality, integration with the other sport areas, and the adjacent zones, use flexibility, [10].

These criteria are important:

- to make compatible and coherent the aspects that characterize the L'Aquila environmental system: high naturalistic territorial value, high administrative-institutional-functional range, and reduced catchment area (in ordinary conditions);

- to build facilities with the following requirements: rapidity of realization, low realization cost, low management cost, and possible energy production with alternative systems (photovoltaic and solar panels integrated in structures).

The proposal of the City of sport and leisure time tries to consider also the characteristics of the city of L'Aquila, its municipal area and its inter-municipal territory. Use integration and flexibility are settled to reach efficient and effective conditions in the management of the City of sport and leisure time. The integration is aimed at combining relationship and coexistence: sport activities and discipline; sport and spare time activities; territory and university sport world; ordinary and extreme regime functionality, leisure, [11].

Another purpose is to create a system between the City of sport and time (multifunctional park) and the other environmental components (Fig. 12). They consist of other sports complexes of L'Aquila, the other territorial sport facilities, the 'Lungo Aterno' River Park, the Vetoio territorial urban park, the Coppito university center, the Coppito hospital, and the Pile industrial area.

Use flexibility is important to optimize the facilities' use in terms of time (seasonal, weekly, and daily maximum utilization), functionality (possible utilization of facilities for different activities), and users (possible utilization of facilities for the maximum number of users: different age, sport, and cultural interest, origin). 


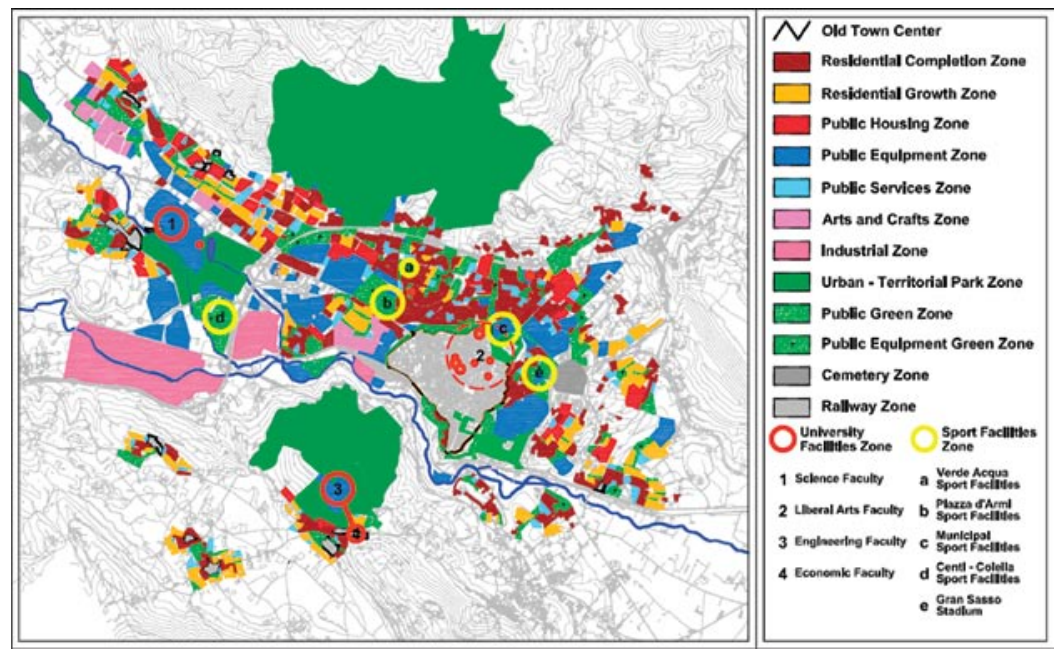

Figure 12: The urban development plan.

In conclusion, the City of sport and leisure time aims at:

- avoiding duplicate facilities that exist in L'Aquila (Viale Gran Sasso Municipal Sports Complex, 'Acquasanta', 'Piazza d'Armi', and 'Verdeacqua' Sports Complex);

- containing a multifunctional facilities complex: Multifunctional Arena (track and field, skating and figure skating, hockey, basketball, handball, volleyball, tennis, five-a-side, climbing; sport, recreational, cultural, and social events); Hockey Arena (skating and figure skating, hockey); Swimming Pool (swimming, synchronized swimming, water polo, diving); Track and Field Arena (track and field, soccer, field hockey); Shooting Range; Bowls Arena;

- holding elementary multifunctional facilities (needed in the territory of L'Aquila): Multifunctional Outdoor Arena (soccer, rugby, field hockey); and Multifunctional Outdoor Arena (tennis, volleyball, basketball, handball, five-a-side).

\subsection{Characteristics of the City of sport and leisure time}

The City of sport and leisure time was conceived for the city of L'Aquila to offer a sports complex with these functional characteristics:

- to hold national and international sports activities;

- to hold cultural, recreational, and social events;

- to become an excellent point of reference of functions for L'Aquila and the surrounding territory;

- to give appropriate sport facilities to the Sports Science Department and to the University Sport Center (C.U.S.) of L'Aquila;

- to contain Civil Defense equipment, in case of emergency events (in L'Aquila there is an high seismic hazard).

The specific planning tasks of the City of sport and leisure time are:

- to make the most of the Aterno River;

- to integrate the river with the sports complex; 
- to create an open system for the river reevaluation in order to support and allow a future requalification of the surrounding river belt areas;

- to get safety measures in flood areas;

- to create a direct relationship between the river and the swimming pool;

- to locate the 'light' facilities (outdoor facilities and equipment with modest volume) near the respective river belt;

- to locate the 'heavy' facilities (indoor facilities and equipment with high volume) far from the respective river belt;

- to create a complementary energy between the swimming pool and the hockey arena;

- to create only one entrance to the City of sport and leisure time for safety reasons;

- to locate a public parking out of the City of sport and leisure time;

- to differentiate between pedestrian and vehicular paths to access the sport facilities.

In Table 4 is shown the dimensional features of the areas and facilities related to the City of sport and leisure time (Fig. 13a and b). [17]. The numbering in Table 4 explains the notation in Fig. 13b.

In Fig. 14, there is a general river section (width from the axis of the flood bed $28 \mathrm{~m}$; height of the bank $3 \mathrm{~m}$ ) in correspondence to a footbridge. The broadening of the river bed is necessary because the Regional Landscape Plan imposes a river belt of $25 \mathrm{~m}$. The section shows the height of the maximum high flow (planning solution of Fig. 10b) decrease until $2.65 \mathrm{~m}$ giving advantages for hydraulic risk mitigation.

The distributional, functional, and dimensional features of the Multifunctional Arena (Fig. 15) are:

- Multifunctional Central Area $\left(4948.00 \mathrm{~m}^{2}\right)$. It includes the Multiuse Field, useful for sport, cultural, recreational, and social events and for Civil Defense, and the Multifunctional Field. The latter includes: a skating rink (200 m); a figure skating rink; a hockey field; two track and field indoor arenas; five track and field indoor springboards; a handball field; a five-a-side field; a basketball field; a volleyball field; a tennis field; and a volleyball training field, [18].

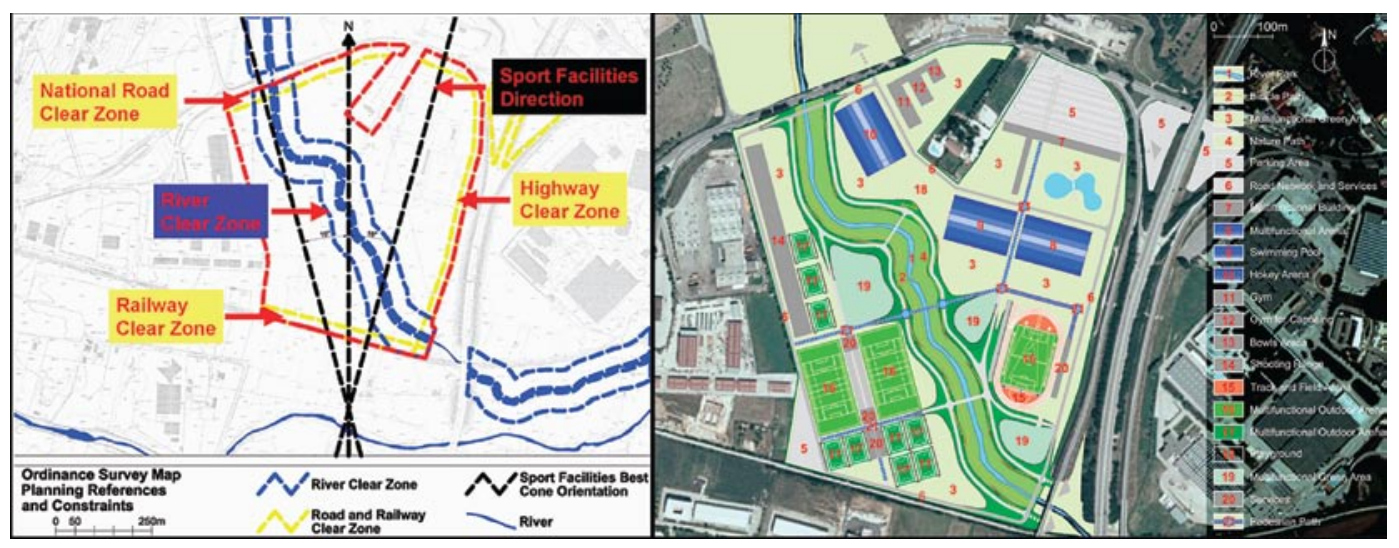

(a)

(b)

Figure 13: (a) Ordinance survey map and (b) areas and facilities of the City of sport and leisure time. 
Table 4: City of sport and leisure time: dimensional characteristics of the areas and facilities.

\begin{tabular}{|c|c|c|c|c|c|}
\hline \multirow{2}{*}{\multicolumn{2}{|c|}{ Sport facilities and areas }} & \multirow{2}{*}{ Quantity } & \multirow{2}{*}{$\begin{array}{l}\text { Unit area } \\
\left(\mathrm{m}^{2}\right)\end{array}$} & \multicolumn{2}{|c|}{ Area } \\
\hline & & & & \multirow[t]{2}{*}{ Uncovered $\left(\mathrm{m}^{2}\right)$} & \multirow[t]{2}{*}{ Covered $\left(\mathrm{m}^{2}\right)$} \\
\hline 1 & River Park & & & & \\
\hline 2 & Bicycle path & 1 & 42,000 & 42,000 & - \\
\hline 3 & Nature path & & & & \\
\hline 4 & Multifunctional Green Area & 1 & 159,255 & 159,255 & - \\
\hline 5 & Parking area & 4 & & 37,900 & - \\
\hline \multicolumn{2}{|r|}{ Not } & 1 & 21,200 & 21,200 & - \\
\hline \multicolumn{2}{|c|}{2} & 1 & 6,500 & 6,500 & - \\
\hline \multicolumn{2}{|c|}{3} & 1 & 5,700 & 5,700 & - \\
\hline \multicolumn{2}{|c|}{4} & 1 & 4,500 & 4,500 & - \\
\hline 6 & Road Network and Services & 1 & 12,000 & 12,000 & - \\
\hline \multirow[t]{3}{*}{7} & $\begin{array}{l}\text { Multifunctional building (ticket office, } \\
\text { safety office, administrative offices, } \\
\text { sport society offices, restaurant, bar, } \\
\text { emergency service, etc.) }\end{array}$ & 2 & 4,200 & - & 4,200 \\
\hline & gon & 1 & 3,000 & - & 3,000 \\
\hline \multirow{2}{*}{\multicolumn{2}{|c|}{ Multifunctional Arena }} & 1 & 1,200 & - & 1,200 \\
\hline & Multifunctional Arena & 1 & 10,300 & - & 10,300 \\
\hline 9 & $\begin{array}{l}\text { Swimming pool (Olympic pool, } \\
\text { diving pool, service structures) }\end{array}$ & 1 & 8,300 & - & 8,300 \\
\hline 10 & Hockey Arena & 1 & 9,000 & - & 9,000 \\
\hline 11 & Gym & 1 & 2,100 & - & 2,100 \\
\hline 12 & Gym for canoeing & 1 & 1,500 & - & 1,500 \\
\hline 13 & Bowls Arena & 1 & 1,000 & - & 1,000 \\
\hline 14 & Shooting range & 1 & 10,000 & - & 10,000 \\
\hline 15 & Track and Field Arena & 1 & 16,000 & 16,000 & - \\
\hline 16 & $\begin{array}{l}\text { Multifunctional Outdoor Arena } \\
\text { (soccer, rugby, hockey) }\end{array}$ & 2 & 11,500 & 23,000 & - \\
\hline 17 & $\begin{array}{l}\text { Multifunctional Outdoor Arena } \\
\text { (handball, five-a-side, volleyball, } \\
\text { basketball, tennis) }\end{array}$ & 9 & 1,500 & 13,500 & - \\
\hline 18 & Playground & 1 & 6,200 & 6,200 & - \\
\hline 19 & Multifunctional Green Area & 3 & & 19,413 & - \\
\hline \multirow[t]{6}{*}{20} & Services and Public Galleries & 6 & & 3,800 & 3,700 \\
\hline & & 1 & 1,000 & - & 1,000 \\
\hline & & 2 & 700 & - & 700 \\
\hline & & 1 & 1,300 & - & 1,300 \\
\hline & & 1 & 1,200 & 1,200 & - \\
\hline & & 1 & 2,600 & 2,600 & - \\
\hline \multirow[t]{3}{*}{21} & Pedestrian path & 1 & 5,700 & 5,700 & - \\
\hline & Total & & & $\begin{array}{l}338,768 \\
(87.12 \%)\end{array}$ & $\begin{array}{c}50,100 \\
(12.88 \%)\end{array}$ \\
\hline & Total & & & \multicolumn{2}{|c|}{$388,868(100.00 \%)$} \\
\hline
\end{tabular}




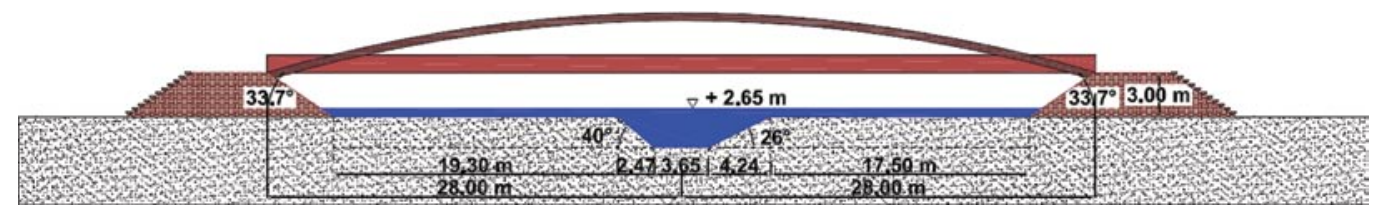

Figure 14: General river section in the City of sport and leisure time.

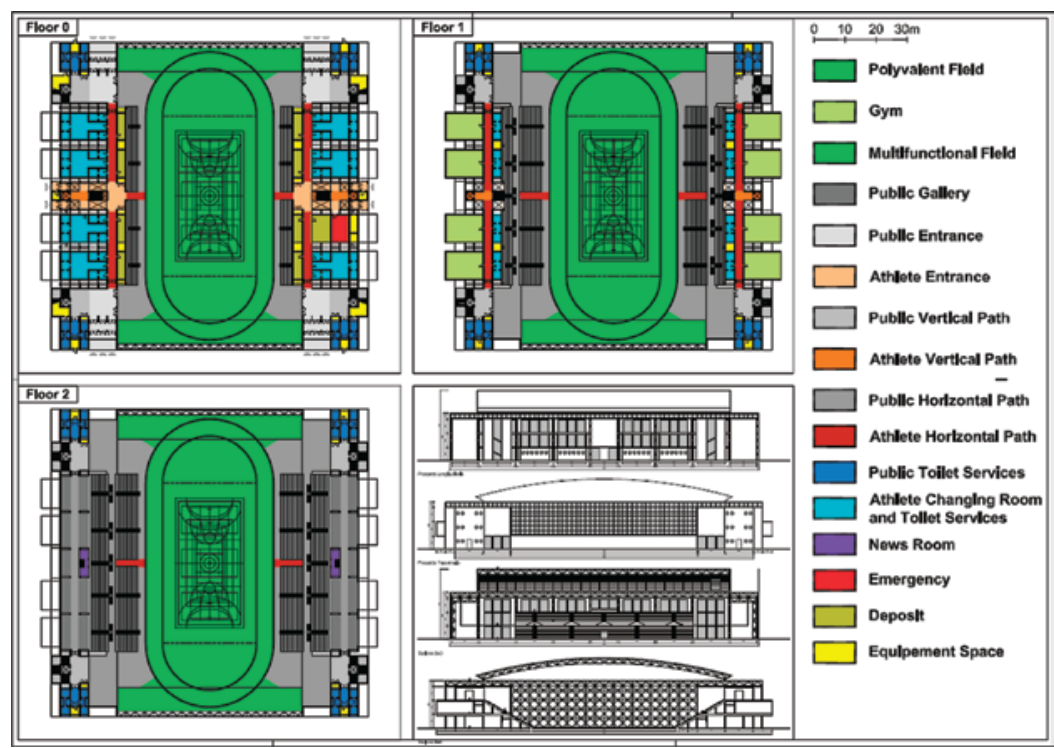

Figure 15: Multifunctional arena.

- Lateral Buildings (three floors). They contain: four public entrances; two athlete entrances; four public vertical path; two athlete vertical paths; six public horizontal paths; four athlete horizontal paths; two public galleries (4.000 box sits); two news rooms $\left(54 \mathrm{~m}^{2}\right)$; an emergency $\operatorname{room}\left(50 \mathrm{~m}^{2}\right)$; eight gyms $\left(800 \mathrm{~m}^{2}\right)$; twelve public toilet services $\left(545 \mathrm{~m}^{2}\right)$; seven athlete changing rooms and toilet services $\left(1.075 \mathrm{~m}^{2}\right)$; two deposits $\left(240 \mathrm{~m}^{2}\right)$; and eighteen equipment spaces $\left(280 \mathrm{~m}^{2}\right)$, [18].

\section{CONCLUDING REMARKS}

The case history presented in this paper is an important example of environmental engineering design, involving the contribution of different specific studies (geology, geotechnics, hydraulics, hydrology, historical geography, ecology, territorial planning, and landscape architeture). The selection of an in situ soil to fill the embankment, in combination with proper design, careful planning, and optimization of the execution techniques, enables the restoration of the hydraulic capacity of the river and the improvement of the stability of the banks and, at the same time, the preservation of the existing environment and the re-naturalization of the site. This case study is appropriate to be applied soon to L'Aquila, because of the earthquake (6 April 2009). In fact, the city and its surrounding areas need new structures for practicing sport activities and for giving new opportunities not only to the local population, but also to the international community. 


\section{REFERENCES}

[1] Amoroso, S., Leopardi, M. \& Totani, G., From geotechnical and hydraulic researches to use of natural materials in mitigation works for river embankments: a case study. Proceeding from Design and Nature IV Comparing Design in Nature with Science and Engineering June 24-26, 2008, The Algarve: Portugal, pp. 281-290, 2008.

[2] Tallini, M., Magaldi, D., Lorè, A., Reale, E. \& Scozzafava, M., Geologia del Quaternario e pianificazione territoriale della piana intramontana L'Aquila-Scoppito (Italia Centrale). Italian Journal of Associazione Georisorse e Ambiente (GEAM), 105(1), pp. 55-67, 2002.

[3] Bertini, T., Cugusi, F., Totani, G. \& Farroni, A., Caratterizzazione geologica e geotecnica dei sedimenti quaternari del settore occidentale della conca aquilana. Proceedings of Department of Structures, Waters and Soil Engineering, University of L'Aquila, 1992.

[4] Marchetti, S., In situ tests by flat dilatometer. Journal of the Geotechnical Engineering Division, ASCE, 106(GT3), pp. 299-321, 1980.

[5] Marchetti, S., Monaco, P., Totani, G. \& Calabrese M., The flat dilatometer test (DMT) in soil investigations a report by the ISSMGE Committee TC16. Proceedings from the Second International Conference on Flat Dilatometer, Washington, DC, pp. 8-48, 2006.

[6] Totani, G., Calabrese, M. \& Monaco, P., In situ determination of $\mathrm{c}_{\mathrm{h}}$ by flat dilatometer (DMT). geotechnical site characterization. Proceedings of the First International Conference on Site Characterization, pp. 883-888, 1998.

[7] Alessandroni, M.G., Leopardi M. \& Remedia G., Deflusso minimo vitale Considerazioni idrologiche sulla portata residuale del Fiume Aterno. Pubblicazione DISAT n.4, 2001.

[8] Leopardi, M. \& Remedia, G., Eventi estremi: le magre e le piene del Fiume Aterno. Associazione Idrotecnica Italiana - Sezione Italia Centrale, 2002.

[9] Leopardi, M. \& Di Nardo, P., Taratura di alcune procedure numeriche per la valutazione delle portate di piena su piccoli e medi bacini privi di dati idrometrici. Regione Abruzzo - Direzione Regionale Gestione Bacini Idrografici, 2004.

[10] Brandizzi, G., Carbone, E. (a cura di), Edilizia per lo sport. Utet,Torino, 2004.

[11] Arnaboldi, M.A., Atlante degli impianti sportivi. Hoepli, Milano, 1982.

[12] Regione Abruzzo, Piano Stralcio Difesa Dalle Alluvioni. Direzione Regionale LL.PP., Aree Urbane, Servizio Idrico Integrato, Manutenzione Programmata Territorio, Gestione Integrata Bacini Idrografici, Protezione Civile, Attività Di Relazione Politica Con Paesi Del Mediterraneo, Deliberazione n.6 del 31.07.2007.

[13] Regione Abruzzo, Quadro Riferimento Regionale. Direzione Parchi, Territorio, Ambiente, Energia, Approvata con D.G.R. 27.12.2007, $\mathrm{n}^{\circ} 1362$.

[14] Regione Abruzzo, Piano Regionale Paesistico. Settore Urbanistica Beni Ambientali, Approvata con D.C.R. 24.04.1990, $\mathrm{n}^{\circ} 3772$.

[15] Comune di L'Aquila, Piano Regolatore Generale. Ufficio del Piano, L'Aquila, 1975.

[16] Comune di L'Aquila, Piano Strutturale. Ufficio del Piano, L'Aquila, 2003.

[17] Comitato Olimpico Nazionale Italiano, Norme Coni per l'impiantistica sportiva. Deliberazione Del Consiglio Nazionale del CONI n. 1379 del 25 giugno 2008.

[18] Federazioni Sportive Italiane, Norme per l'impiantistica sportiva. Varie Annualità. 